\title{
trabalhonecessário
}

issn: $1808-799 X$

ano 7 - número 8 - 2009

\section{Juventude e Trabalho: notas e reflexões sobre a formação profissional mediada pela "Lei do Aprendiz" (Lei 10.097/00)}

Ozias de Jesus Soares - ozias.soares@bol.com.br

\section{RESUMO}

O texto apresenta notas de uma pesquisa com respeito à Lei da Aprendizagem e a experiência de jovens trabalhadores em algumas empresas situadas no Rio de Janeiro. Situa historicamente a formação profissional que ocorre nos chamados programas de aprendizagem, apontando as principais determinações que cercam esta proposta. Indicamos contradições e possibilidades presentes na esfera do mundo do trabalho e juventude. Destacamos a ideologia que reforça o caráter dual da educação brasileira em nossos dias, observando que na sociedade capitalista o trabalho para jovens apresenta-se, via de regra, como disciplinamento, manutenção da ordem social, tomado, enfim, como "preventivo dos males sociais".

PALAVRAS-CHAVE: trabalho, educação, juventude, aprendiz, formação profissional.

\begin{abstract}
"A escola profissional não se deve transformar numa incubadora de pequenos monstros aridamente instruídos em função de um ofício, sem idéias gerais, sem cultura geral, sem alma, possuidores apenas de um olhar infalível e de uma mão firme". ${ }^{1}$
\end{abstract}

No contexto da Itália de início do século XX, Antonio Gramsci dirige suas críticas à constituição de um ensino caracteristicamente dual. Colocou em evidência que a escola profissional era notadamente destinada às classes trabalhadoras tendo em vista uma ocupação subalternizada no mundo do trabalho ${ }^{2}$. Sendo assim, os saberes ali circulantes se limitavam apenas ao mínimo à execução de tarefas fragmentadas e parceladas na esfera da produção. Fora deste campo de ação não Ihes cabia um ensino profissional que avançasse no domínio da cultura geral, no conhecimento dos fundamentos 


\section{trabalhonecessário}

issn: $1808-799 \mathrm{X}$

ano 7 - número 8 - 2009

científico-tecnológicos e econômico-filosófico da produção da vida social, enfim, um ensino para a formação de dirigentes. Gramsci usa, assim, uma metáfora, apresentada na epígrafe acima, para caracterizar aquela formação aligeirada e ideologicamente comprometida com a perenização do status quo: a produção em série de força de trabalho através de uma incubadora de uma incubadora de pequenos monstros. A "incubadora" ali - no sentido da formatação, conformação e preparação da força de trabalho - mostra total ambiência e coerência de propósitos com forças que regem o atual mercado de trabalho.

Trazemos, portanto, neste texto algumas reflexões fruto de pesquisa de mestrado $^{3}$, para apontar algumas determinações e circunstâncias que norteiam hoje os chamados "programas de aprendizagem", ou comumente conhecido como formação de aprendizes, aos quais identificamos na sua forma e propósitos com objetivos bastante similares daqueles observados desde 0 início do século XX. Parafraseando aquela fala de Gramsci, preferimos usar aqui o termo "incubadora de monstrinhos", sem perda do sentido atribuído pelo autor.

O que aqui chamamos de Lei do Aprendiz, em função do uso corrente desta expressão, trata-se, na verdade da Lei 10.097/00, denominada Lei da Aprendizagem. O termo Lei do Aprendiz refere-se, assim, aos sujeitos beneficiários de uma legislação originalmente posta pela Consolidação das Leis Trabalhistas de 1943, e que agora é re-escrita em vários de seus dispositivos, tendo em vista a emergência da Constituição de 1988 e do Estatuto da Criança e do Adolescente (Lei 8.069/90). A pesquisa que aqui aludimos buscou uma interlocução com sujeitos dos chamados "programas de aprendizagem" (art. 428, Lei 10.097/00), quer sejam profissionais que acompanham os aprendizes nas empresas ou os próprios jovens aprendizes que vivenciam o cotidiano desses programas. 


\section{trabalhonecessário}

issn: 1808-799X

ano 7 - número 8 - 2009

Enorme contingente de jovens aprendizes (situados na faixa entre 14 e 24 anos), não apenas participam de uma etapa que adquirem conhecimentos básicos sobre a esfera do mundo do trabalho como ainda, vendem a sua força de trabalho na relação estabelecida no cotidiano das empresas e instituições formadoras.

Considerando o quadro de desemprego juvenil no Brasil, bem como os diversos dilemas enfrentados nesta etapa da vida num contexto de múltiplas lacunas nos planos sócio-econômico e de políticas públicas efetivas, ressaltamos que o tipo de formação mediada pela Lei da Aprendizagem (Lei 10.097/00) - que norteia, portanto, os programas de aprendizagem acima citados - opera com um pressuposto basilar que são as situações de vulnerabilidades sociais vividos por jovens das classes trabalhadoras; ou seja, trata-se da formação de jovens trabalhadores que vivem o imperativo da sobrevivência, que entre tantas interfaces da vida, precisam inventar "estratégias econômicas para defender-se das injustiças sociais"

Esta formação possui algumas particularidades que merecem destaque: ela se dá no próprio processo de trabalho, mediada pela Lei da Aprendizagem; ela acontece em parceria com empresas e instituições qualificadas em formação técnico-profissional - aqui expressa através do "Sistema S" , Escolas Técnicas e Organizações sem fins lucrativos que tenham registro nos conselhos de direitos da criança e adolescente; esta formação não se encontra atrelada a qualquer nível de ensino, com isso, indistintamente, jovens que estejam iniciando sua trajetória escolar, retornando aos bancos escolares, concluindo o ensino fundamental ou cursando o ensino médio, podem participar deste programa de formação. Valendo aqui ressaltar que esta formação assume - dada a sua forma e conteúdo - muito mais um caráter de programa assistencial e menos de formação pelo/para o trabalho propriamente. 


\section{trabalhonecessário}

issn: $1808-799 \mathrm{X}$

ano 7 - número 8 - 2009

Uma questão de fundamental importância ao analisarmos os programas de aprendizagem é a sua força enquanto uma política pública: a Lei da Aprendizagem obriga todas as empresas de médio e grande porte a contratarem um número de "aprendizes" (como são denominados os jovens acima de 14 anos e com menos de 24) no mínimo de 5\% e no máximo 15\% de seu quadro de funcionários (art. 429). Nos dispositivos anteriores (CLT, 1943), apenas as empresas industriais, comerciais, de transporte e pesca eram obrigadas, daí a participação do Sistema S. Sendo assim, uma grande questão que se coloca aí seria: temos uma força de lei que, se levada a cabo, será de resultados e proporções razoáveis no que diz respeito à formação de mão-deobra semi-qualificada. Temos, portanto, uma questão de formação de mão-deobra assalariada, com liberdade a que instituições e escolas técnicas, além do Sistema $\mathrm{S}$, formulem programas de formação profissional básica em parceria com o mundo empresarial.

Considerando o modelo de Estado que vem sendo gestado, em especial após a década de 1990, no qual observamos novos contornos nos papéis atribuídos à sociedade civil, e as ações sob a chancela de responsabilidade social povoam tanto o mundo do trabalho como as pessoas comuns, cabe indagar: qual o novo desenho do Estado brasileiro em termos de políticas de formação profissional do jovem das classes trabalhadoras? De que forma e com quais conteúdos vem se dando a inserção desses jovens no mundo do trabalho através dos Programas de Aprendizagem mediados pela Lei 10.097/00 (Lei da Aprendizagem)? E, por fim, quais as relações destas iniciativas com o contexto mais amplo da formação (e conformação) do trabalhador atualmente?

Analisar algumas realidades particulares pode nos servir de "posto de observação" para contextos mais amplos. $\mathrm{Na}$ pesquisa realizada, procuramos investigar a gênese e os significados históricos da Lei da Aprendizagem e as atuais políticas de inserção dos jovens no mundo do 


\section{trabalhonecessário}

issn: $1808-799 \mathrm{X}$

ano 7 - número 8 - 2009

trabalho, bem como as relações entre trabalho e educação que se constituem no processo de formação de jovens trabalhadores participantes de Programas de Aprendizagem. Alguns pilares, portanto, podem ser descritos aqui como características da maioria dos programas de aprendizagem, a saber: (1) as Ong's devem trabalhar regidas pela Lei da Aprendizagem e terem, conforme apontamos acima, registro no conselho municipal de direito da criança e adolescente; (2) o público-alvo das ações dos Programas de Aprendizagem são jovens das classes populares, portanto, com características de renda, escolaridade, participação, consumo, entre outros aspectos, bastante em comum.

Sobretudo, é preciso destacar que o empresariado, grosso modo, continuará a visar a produção, o lucro, ainda que justificando suas ações na chamada responsabilidade social ou ativismo empresarial (cf. Beghin, 2005). No plano imediato, portanto, concluímos que não se vislumbra a formação ampliada do jovem trabalhador, mas os interesses particulares da maioria das empresas. Enquanto persistir o sistema que engendra tais ações acima citadas, as críticas e observações tecidas na pesquisa realizada e nas linhas aqui apontadas terão sua validade.

Neste sentido, cabe aqui ressaltar que ao longo da história do Brasil houve uma vinculação entre o ensino profissional e a assistência social, em especial aos caracterizados como desvalidos da sorte (cf. Bazílio, 2001). Os "menores", termo para se referir não apenas a situação de capacidade ou incapacidade legal, mas especificamente à infância pobre, não foram, todavia, os únicos a serem os destinatários da política de assistência/profissionalização. Segundo Manfredi, desde o início da República, adentrando no século $X X$, a educação profissional era destinada aos setores populares tendo em vista a sua incorporação como trabalhadores assalariados. Era, concordando com a autora, um processo de qualificação aliado ao disciplinamento dos trabalhadores livres dos setores urbanos ${ }^{6}$. 


\section{trabalhonecessário}

issn: $1808-799 \mathrm{X}$

ano 7 - número 8 - 2009

À luz dos debates sobre o tema e os autores que versam sobre a formação profissional de jovens, concluímos que ainda vicejam as idéias de disciplinamento e de moralização dos pobres nas ações sob esta chancela. Há, portanto, uma precedência dos "valores", das "atitudes" e do relacionamento, das "boas maneiras" e do asseio corporal e pessoal, sobre outras dimensões do processo educativo. Considerado de uma perspectiva crítica, para além das aparências do fenômeno, diríamos que o caráter preventivo de males sociais delineia a própria essência da Lei da Aprendizagem. Considerando os momentos históricos da formação profissional, diríamos que estamos diante de uma nova pedagogia da docilidade.

A necessidade imposta pela ordem social (cf. Souza et alli, 1996) trouxe à tona a reformulação da CLT (1943) referente ao "trabalho do menor". Tendo sido regulamentada em 2005, a Lei 10.097/00 - Lei da Aprendizagem, traz, por sua vez, novos (e antigos) atores para o centro da cena. Dentre estes encontram-se as chamadas organizações não governamentais.

Dado o perfil dos programas de aprendizagem, destacamos que a Lei da Aprendizagem insere-se dentro de um processo de flexibilização das relações de trabalho no contexto das ações ligadas à reestruturação produtiva. Esta Lei levou cerca de cinco anos para ser regulamentada ${ }^{7}$, ainda que alguns autores considerem que esta modalidade de legislação tenha aplicação imediata (cf. Minharro, 2003). Ela é tida por muitos como uma lei que vem garantir uma formação profissional aos jovens e reduzir o fosso das desigualdades de inserção no mercado de trabalho. A participação popular no tocante à pressão para a regulamentação desta Lei pode ser um termômetro para balizarmos a quem de fato interessa uma legislação desta natureza. A única reação (que não podemos chamar de "protesto" ou "movimento") de que tivemos notícia - após quase cinco anos - trata-se de uma manifestação cancelada um dia antes da regulamentação da Lei da Aprendizagem pelo Presidente Luiz Inácio Lula da Silva ${ }^{8}$. 


\section{trabalhonecessário}

issn: $1808-799 \mathrm{X}$

ano 7 - número 8 - 2009

Reconhecemos o tamanho dos problemas sociais a ser enfrentado no contexto brasileiro, dado, em especial, seus determinantes e particularidades históricas. Certamente, a Lei da Aprendizagem insere-se num momento em que a crise do desemprego estrutural atinge em cheio a juventude trabalhadora (cf. Pochmann, 2000), e urge a necessidade de pensar formas de reversão de um quadro que o próprio sistema produziu. Precisamos, no entanto, não desconsiderar de que reeditamos, grosso modo, a "legitimação da exploração" de jovens trabalhadores. Este tipo de formação carrega consigo marcas ideológicas da própria sociedade que o sustenta. Soma-se aí a questão da dilatação da idade do aprendiz para 24 anos, conforme o decreto $5.598 / 05^{9}$.

O trabalho, entendido enquanto preventivo dos males sociais, como disciplinamento da força de trabalho e como um amortecedor das crises que assolam a juventude, em especial aquela maioria oriunda das classes populares, assume, na verdade, um discurso moralizador e uma valorização que não considera prejuízos imediatos tanto para a formação individual quanto para a organização dos trabalhadores. Essas e outras contradições no terreno da prática dos Programas de Aprendizagem nos remetem ainda a considerar a dimensão ontológica do trabalho e a formação sob a ótica da omnilateralidade. O trabalho, tal qual o realizado pelos jovens aprendizes, perde a sua dimensão ontológica nos programas de aprendizagem?

Se considerarmos que o objetivo do capital é reduzir todo o trabalho complexo a trabalho simples $^{10}$, e que isto implica uma desqualificação crescente do trabalho, acreditamos que passa ao largo a perspectiva de uma educação integral e politécnica. Esta modalidade de iniciação profissional (de acordo com a Lei 10.097 trata-se de uma "formação técnico-profissional metódica", art. 428), situa-se numa perspectiva de "polivalência", considerando discursos que versam sobre a "pedagogia das competências" (cf. Ramos, 2001) e a aquisição de graus crescentes de "empregabilidade". Lessa, em sua pesquisa sobre o Programa Trabalho Educativo Convênio UERJ/FIA 


\section{trabalhonecessário}

issn: $1808-799 \mathrm{X}$

ano 7 - número 8 - 2009

(Fundação para Infância e Adolescência), diz que a formação polivalente se inscreve satisfatoriamente no contexto da flexibilidade, embora não possa ser negada a sua existência na conjuntura fordista, já que ali também existiam trabalhadores especializados que dominavam a variedade da ação produtiva. Nesta perspectiva, a autora diz que 0 trabalho-aprendizagem que os adolescentes do referido programa se inseriam era uma expressão de "polivalência precária", uma vez que as "tarefas extremamente simples", fragmentadas e mecânicas, não se podia caracterizar um trabalho visto sob aquela ótica ${ }^{11}$.

No que se refere ao programa sob a Lei da Aprendizagem nas instituições em que pesquisamos ${ }^{12}$, existe todo um terreno e cenário para a prática da polivalência considerando que esta lei estabelece que a aprendizagem se dê através de "atividades teóricas e práticas, metodicamente organizadas em tarefas de complexidade progressiva desenvolvidas no ambiente de trabalho" (Art. 428, $\S 4^{\circ}$ ). Entretanto, a partir dos dados trazidos pela pesquisa, sejam pelas nossas observações no espaço concreto de trabalho dos jovens nas empresas, sejam pelas informações trazidas nas entrevistas ou nas exaustivas observações, concluímos com a mesma análise de Lessa, ou seja, estamos diante de uma "polivalência precária". A polivalência, defendida enquanto as competências, atributos e habilidades do trabalhador é expressa através dos discursos postulados pelas empresas e pelas organizações mediadoras dos programas de aprendizagem. Imersos, assim, no atual momento em que do trabalhador é requerido um sem número de habilidades, os operadores dos programas nas empresas insistem no discurso da "necessidade" de que os adolescentes "busquem cursos", "enriqueçam o currículo", "façam cursos de idiomas", "entendam de informática", entre outras solicitações. Basta olharmos para a construção da maioria dos currículos dos programas: Relações Humanas, Cidadania e Ética, Linguagem, Empreendedorismo, Gerenciamento de Carreira [ou "empregabilidade"], Rotinas Administrativas, Universo Tecnológico, Cálculos 


\section{trabalhonecessário}

issn: $1808-799 \mathrm{X}$

ano 7 - número 8 - 2009

Comerciais, Educação Digital, Arquivo, Leis Trabalhistas, Educação ambiental e Atividades Culturais. Num primeiro olhar, diríamos que tais conteúdos estariam dentro do razoável em termos de proposta de formação inicial. Nos limites impostos pela prática social historicamente e ideologicamente condicionada resta, entretanto, aos adolescentes participantes de muitos desses programas uma formação aligeirada, tarefas repetitivas, cansativas e em desacordo com os pressupostos legais do Estatuto da Criança e Adolescente (Lei 8.069/90) e da própria Lei da Aprendizagem. Somando-se ainda as visões caritativas e preconceituosas que recaem sobre eles, como se fossem dignos de "pena".

Apesar da Lei da Aprendizagem estabelecer a obrigatoriedade da freqüência escolar, a maioria dos programas não pressupõe uma vinculação do trabalho manual e intelectual, na perspectiva gramsciana, unitária. Logicamente, para Gramsci, todo o trabalho por mais rudimentar que seja exige um esforço intelectual e não apenas físico. No entendimento de Kuenzer, citando Marx, se o conhecimento é elaborado socialmente a partir do trabalho dos homens que estabelecem relações entre si na produção da existência, processo pelo qual se constitui a sua consciência, é inegável o fato de que o operário produz conhecimento ${ }^{13}$. Entretanto, o trabalho se desqualifica sob o capitalismo, aliena e enrijece a potencialidade humana. A escola "interessada" do capital oferece, portanto, uma educação desqualificadora. Enfatizamos, portanto, que, não apenas a escola (fundamental ou média) dos jovens aprendizes insere-se neste campo, mas principalmente a aprendizagem do/no trabalho que executam é, de igual modo, desqualificadora.

Neste sentido, no contexto do trabalho com a Lei da Aprendizagem, as organizações não governamentais aparecem como peças-chave. Muitas das quais identificadas com o chamado terceiro setor funcionam em consonância com o projeto neoliberal (cf. Boito Jr., 1999). De acordo com Montaño, o capital luta por instrumentalizar a sociedade civil - torna-la dócil, 


\section{trabalhonecessário}

issn: $1808-799 \mathrm{X}$

ano 7 - número 8 - 2009

desestruturada, desmobilizada, amigável. Conforme este autor, o debate sobre terceiro setor, como ideologia, transforma a sociedade civil em meio para o projeto neoliberal desenvolver sua estratégia de reestruturação do capital ${ }^{14}$. A grande parceria das organizações não-governamentais com as empresas, a fim de trabalharem os programas para aprendizes, legitimada agora com a Lei da Aprendizagem, remete-nos às reflexões de Montaño acima. Os formadores (as próprias empresas que oferecem as vagas) e os orientadores (os funcionários das empresas que oferecem as vagas de aprendizes) trabalharão sob que lógica? A da empresa ou a da ONG? Seriam propostas diferentes que confluem para um mesmo horizonte?

Observamos, todavia, que há uma clara subordinação dessas organizações em relação às empresas. Para os profissionais envolvidos nos Programas, não se pode trabalhar com determinados conteúdos que poderiam causar eventuais constrangimentos, ou seja, não se pode "colocar os meninos contra a empresa" (sic.). Na visão que se construiu a respeito desses jovens há que se registrar que muitos profissionais nas próprias empresas não respeitam a condição do jovem como um aprendiz e quer que tão somente "esses meninos façam o seu trabalho" e "não causem problemas". Conforme vivenciamos e percebemos no trabalho de campo, existem algumas dificuldades em estar dentro da empresa para a realização de um trabalho com os jovens. Um trabalho mediado por conteúdos mais críticos, colocaria em risco a própria sobrevivência de um convênio da Instituição de formação com a empresa e, em conseqüência, a manutenção dos serviços e dos empregos dessas organizações.

Manfredi (op. cit.) e Montaño (op. cit.) trabalham com dados de que mais de um milhão de pessoas estariam empregadas nas organizações do chamado terceiro setor. Neste sentido, manter um quantitativo tão expressivo e crescente de empregados não é tarefa fácil. Montaño nos dá alguns 


\title{
trabalhonecessário
}

issn: $1808-799 \mathrm{X}$

ano 7 - número 8 - 2009

esclarecimentos sobre a captação de recursos para estas Ong's. Segundo críticas feitas pelo referido autor,

\begin{abstract}
"A missão [da ONG] deve estar de acordo, não com a filosofia, valores, princípios, objetivos da organização ou de seu públicoalvo, mas com 'o perfil, os interesses e as exigências do doador potencial'. Isto é, se o 'perfil e interesses' do doador potencial estiverem em desacordo com a filosofia e valores da organização requerente, na melhor das hipóteses esta última renuncia a esta fonte de recursos; mas na hipótese mais realista /.../, a organização adapta sua 'missão' ao 'perfil' do doador, ou torna sua filosofia tão laxa, flexível, vazia, que lhe permita 'negociar' com praticamente qualquer 'doador potencial" "
\end{abstract}

A maioria das organizações não governamentais, segundo Montaño, depende de recursos e se filia, portanto, a qualquer "matriz filosóficoideológica" dos potenciais doadores. Embora, evidente, seja preciso reconhecer que há instituições que trabalham numa direção contrahegemônica, contando com excelentes profissionais, do ponto de vista técnico e político. Esses mesmos profissionais - possuidores apenas de sua força de trabalho, todavia, acabam por viver de perto as contradições entre os discursos e os limites impostos pela prática cotidiana. Resta, assim, nos perguntar qual seria, pois, o caminho da superação e da ruptura de modelos reconhecidamente enrijecidos? Talvez a resposta esteja nas próprias contradições do modelo.

De acordo com Beghin, são nos espaços plurais, não consensuais, e por vezes, conflituais, "que impulsionam a construção de uma verdadeira alternativa às estratégias baseadas na rentabilidade a curto prazo e na competitividade"15. Entendemos que a Lei da Aprendizagem longe está de apontar um caminho de transformação da realidade do trabalho e da educação de contingentes de jovens das classes trabalhadoras. Esta mesma lei, no 


\section{trabalhonecessário}

issn: $1808-799 \mathrm{X}$

ano 7 - número 8 - 2009

entanto, referendando a entrada de milhares de jovens no mundo do trabalho ainda que sob o capital - oferece a potencialidade da "criação dos próprios coveiros" do sistema, como diria Marx no Manifesto ${ }^{16}$. Os jovens têm um contato com um universo de relações de trabalho assalariado que até então não vivenciavam. Trata-se de um mundo novo para a maioria deles. É preciso ainda ressaltar que muitos possuem uma visão crítica das contradições entre capital e trabalho ${ }^{17}$.

Apesar da aparente ausência de um trabalho político, da conscientização e do conhecimento da esfera dos direitos na maioria dos Programas de Aprendizagem, não se pode desconsiderar que esses sujeitos sejam meramente passivos diante de um quadro geral de dominação e de exploração de sua força de trabalho. Enquanto não está posto o horizonte de uma transformação mais profunda da sociedade e da derrocada do atual sistema capitalista, diríamos que ele deve ser buscado no terreno da experiência concreta dos sujeitos e na construção de novos modelos de formação e de trabalho. Conforme aponta Sennett, "uma idéia precisa suportar o peso da experiência concreta, senão se torna mera abstração"18. Desse modo, acreditamos que é na experiência concreta, portanto, o terreno da instauração da luta e da tomada de consciência para a transformação das relações.

Cabe aqui retomar a questão colocada acima com respeito à dimensão ontológica do trabalho do aprendiz. Este jovem tem na empresa um espaço de sociabilidade, de relações, de contato com o universo do trabalho, que mesmo sob o capital e sua característica de expropriação, a dimensão ontológica do trabalho enquanto constituinte do ser não se apaga sumariamente. Na ótica da politecnia e da omnilateralidade, a maioria dos programas de formação dos aprendizes, passa ao largo, conforme inscreve as próprias determinações e condicionantes históricos. Mas, acreditamos que é ali naquele espaço que o jovem pode apreender e aprender a teia de relações que 


\section{trabalhonecessário}

issn: $1808-799 \mathrm{X}$

ano 7 - número 8 - 2009

constitui o trabalho assalariado na sociedade, na forma específica de relações capitalistas e o modo mesmo de como enfrentar os seus principais dilemas. É ali que ele percebe a organização dos trabalhadores e o sentido de uma coletividade. Ali pode ainda juntar-se a tantos outros jovens que enfrentam e vivem os mesmos problemas, dilemas e lutas. É ali que ele também se identifica enquanto um trabalhador.

Da mesma forma, acreditamos que a Lei da Aprendizagem, ao legitimar a presença das organizações não governamentais de atendimento ao adolescente (art. 430, Lei 10.097/00), também abre espaço para que estas organizações formulem uma proposta de aprendizagem que insira as múltiplas dimensões do processo educativo pautado numa outra direção. O programa de aprendizagem comporta uma parte teórica que pode ser desenvolvida pelas organizações, enquanto um espaço potencial de autonomia. Resta saber, no entanto, qual a direção político-ideológica a ser tomada neste caso. Resta ainda saber explorar as brechas para que contingentes enormes de jovens compreendam a esfera do trabalho não apenas como criador de valores de troca, mas como espaço de desenvolvimento do ser social.

É preciso, pois, a construção de um programa de aprendizagem que desenvolva os aspectos políticos que envolvem a questão do trabalho com os jovens, as dimensões postas na esfera do mundo do trabalho, os conteúdos técnicos - aliados à formação básica escolar - e, por fim, o horizonte das transformações sociais. Resta, portanto, construir projetos que se insiram numa perspectiva contra-hegemônica de formação profissional desses jovens trabalhadores para além do disciplinamento, da moralização, do aprendizado da subserviência.

Defendemos que a formação do jovem no processo de trabalho caminhe "para além de uma incubadora de monstrinhos". E, como diria o próprio Gramsci, citado na epígrafe deste texto, a qual repetimos aqui: "A 


\section{trabalhonecessário}

issn: $1808-799 \mathrm{X}$

ano 7 - número 8 - 2009

escola profissional não se deve transformar numa incubadora de pequenos monstros aridamente instruídos em função de um ofício /.../ possuidores apenas de um olhar infalível e de uma mão firme"

A "mão firme" do trabalhador precisa estar presente no trabalho. Mas não apenas a mão, mas todas as suas potencialidades e conhecimentos, não engessados, logicamente, por políticas aligeiradas de formação e de contenção da pobreza, do "apagar de incêndios". Estamos certos, todavia, de que não se trata de uma tarefa fácil, mas torna-se possível a partir do horizonte da luta, na articulação do plano do concreto e do conhecimento.

Bibliografia

Bazílio, Luiz C. Crianças e Adolescentes no centro da cena: Trajetória e consolidação de um grupo de pesquisa. Rio de Janeiro: Ravil, 2001.

Boito Jr. Política neoliberal e sindicalismo no Brasil. São Paulo: Xamã, 1999.

Minharro, Erotilde Ribeiro dos Santos. A criança e o adolescente no Direito do Trabalho. São Paulo: LTR, 2003.

Pochmann, Marcio. O trabalho sob fogo cruzado. Exclusão, desemprego e precarização no final do século. São Paulo: Contexto, 2000.

Ramos, Marise. A Pedagogia das Competências: Autonomia ou Adaptação? São Paulo: Cortez, 2001.

Souza, Ana Aparecida Arguelho et alli. Sobre(o)viver de crianças e adolescentes: uma reflexão acerca do método de pesquisa. In: Trabalho Necessário - Revista eletrônica do NEDDATE, ano 4, número 4, Niterói, UFF, 2006. 
issn: $1808-799 X$

ano 7 - número 8 - 2009

\section{NOTAS}

\footnotetext{
${ }^{1}$ Gramsci, in Avanti!, Edição de Turim, 24/12/1916, apud Cavalcanti e Piccone, s/d.

${ }^{2}$ Gramsci, ibid.

3 Dissertação de Mestrado defendida em 2006 junto ao Programa de Pós-graduação em Educação, Universidade Federal Fluminense, campo "Trabalho e Educação", orientada pela professora Dra. Lia Tiriba, sob o título "Para além de uma incubadora de monstrinhos: a formação do jovem trabalhador sob a Lei da Aprendizagem".
}

4 Tiriba, Lia. Economia Popular e cultura do trabalho: pedagogia(s) da produção associada. ljuí: Editora Unijuí, 2001. p. 25.

${ }^{5}$ SENAI - Serviço Nacional de Aprendizagem Industrial, SENAC - Serviço Nacional de Aprendizagem Comercial, SENAR - Serviço Nacional de Aprendizagem Rural, SENAT - Serviço Nacional de Aprendizagem do Transporte e SESCOOP - Serviço Nacional de Aprendizagem do Cooperativismo.

${ }^{6}$ MANFREDI, Silvia Maria. Educação Profissional no Brasil. São Paulo: Cortez, 2003. P.80.

${ }^{7}$ A regulamentação da Lei da Aprendizagem aconteceu no dia 31 de novembro de 2005.

${ }^{8}$ Relembramos que a manifestação foi orquestrada pela Abrinq, Gol de Letra e Ethos para o dia 01 de dezembro. A regulamentação aconteceu no dia 31 de novembro.

${ }^{9}$ Uma legislação assemelhada a esta no contexto da França, no entanto, causou desde o ano de 2005 revoltas intensas entre os jovens. Ali o Contrato do Primeiro Emprego (CPE), definiria que os jovens com menos de 26 anos poderiam ser demitidos pelos empregadores no intervalo de até dois anos do início da contratação. A medida causou as revoltas noticiadas em todos os mass media. Aqui a Lei da Aprendizagem foi alargada dos 18 para os 24 anos pelo Governo em dezembro de 2005.

${ }^{10}$ Marx, apud Frigotto, Gaudêncio. In: Fazendo pelas mãos a cabeça do trabalhador: o trabalho como elemento pedagógico na formação profissional. Cadernos de Pesquisa, n.47, nov. 1983. P. 26.

${ }^{11}$ Lessa, Simone Elida do Carmo. A formação no Programa de Trabalho Educativo da FIA/RJ. Dissertação de Mestrado, 246f. Niterói: Universidade Federal Fluminense, 2004. p.220.

12 Durante os anos de 2002 a 2006, observamos o cotidiano da instituição São Martinho (Rio de Janeiro) que opera com programa de formação de adolescentes desde 1986. Neste período, tive a oportunidade de acompanhar, como Pedagogo contratado pela instituição, experiências no programa de aprendizagem da Associação São Martinho conveniado com várias empresas situadas no Rio de Janeiro (Eletrobrás, Petrobrás, Light, Petros, IRB, Kaiser, Ipiranga, BNDES, CEPEL, Fiocruz), terreno, portanto, da nossa pesquisa de mestrado acima citada.

${ }^{13}$ Marx, apud Kuenzer, Acácia. In: A pedagogia da fábrica: as relações de produção e a educação do trabalhador. São Paulo: Cortez/Autores Associados, 1985. P. 183.

${ }^{14}$ Montaño, Carlos. Terceiro Setor e questão social - crítica ao padrão emergente de intervenção social, São Paulo, Cortez, 2005. P. 233.

${ }^{15}$ Beghin, Nathalie. A filantropia empresarial: nem caridade nem direito. São Paulo: Cortez, 2005. P. 106. 
issn: $1808-799 \mathrm{X}$

ano 7 - número 8 - 2009

\begin{abstract}
${ }^{16}$ Marx, Karl. Manifesto do Partido Comunista. São Paulo: Cortez, 1998. p. 20.
17 Cabe aqui destacar algumas falas de jovens sujeitos da pesquisa de campo para ilustrar esta afirmativa: "Quando eu entrei na empresa foram muito rápido assim que... me ensinaram. .. e quando a gente não sabe a gente tem que procurar... porque eles não vão parar o trabalho deles pra nos ensinar... então, quer dizer, outros menores que estão há mais tempo que a gente, eles que tem que nos ensinar... porque... então 'quem vai ter que ensinar sou eu' porque as pessoas maiores de idade que estão lá não vão ter a paciência de ensinar... " (Aprendiz, Paloma).

"A oportunidade é maior pros meninos... o pessoal tem muito medo de menina por causa dessa questão da gravidez..." (Aprendiz, Ricardo).

"Já me senti prejudicado [no trabalho]. Eu acho que existem pessoas aqui que gostam de fazer armadilhas pro jovem cair e às vezes à gente cai... já aconteceu comigo já... tem discriminação... principalmente de gênero então é o que mais acontece!... tem certos setores que não trabalham com meninas por causa dessa questão de... tem outra coisa: as pessoas levam muito em conta a aparência... na empresa as pessoas costumam morar, assim, em Copacabana, Leblon... zona oeste, eles nem sabem onde é isso! Pra mim isso não atrapalha em nada... eu não ligo muito não pra essas coisas [da discriminação]" (Aprendiz, Bruno).

"A empresa sempre... assim nunca foi incorreta com os funcionários, e é uma empresa privada, você sabe... uma vez só que o sindicato chegou lá na porta e os funcionários ficaram de longe.. nem participaram, eu achei engraçado: se é algo que ia te beneficiar, se é uma briga que vai lutar por seus direitos... mas ninguém foi... ninguém participou..." (Aprendiz, Ricardo)

"Lá tem o sindicato dos trabalhadores... lá dentro... é, o sindicato é lá dentro, o sindicato da empresa... é legal, assim, quando quer aumento eles ficam na porta da empresa, o pessoal reivindicando, eu acho legal porque é uma forma do pessoal da empresa não se constranger... tem o líder, a pessoa que vai lá na reunião com o Presidente pra pedir aumento... embarreiravam o presidente de entrar na empresa, fechavam o estacionamento e ninguém entra até que ... ficava todo mundo na porta.. ninguém entrava, nem o presidente entrava... e conseguiam muito pouco, mas conseguiam. Da última vez agora, enquanto eles não conseguiam o acordo, eles colocavam um valor, enquanto eles não conseguiam aquilo eles continuaram fazendo a greve...". (Aprendiz, Lígia).
\end{abstract}

${ }^{18}$ Sennett, Richard. A corrosão do caráter. Conseqüências pessoais do trabalho no novo capitalismo. $\left(4^{a}\right.$ ed.). Rio de Janeiro: Record, 2000. p. 10.

Ozias de Jesus Soares: Doutorando do Programa de Pós-graduação em Ciências Sociais da UERJ; Mestre em Educação (UFF); Técnico em Educação do Instituto do Patrimônio Histórico e Artístico Nacional e Professor substituto da Faculdade de Educação da UERJ. 